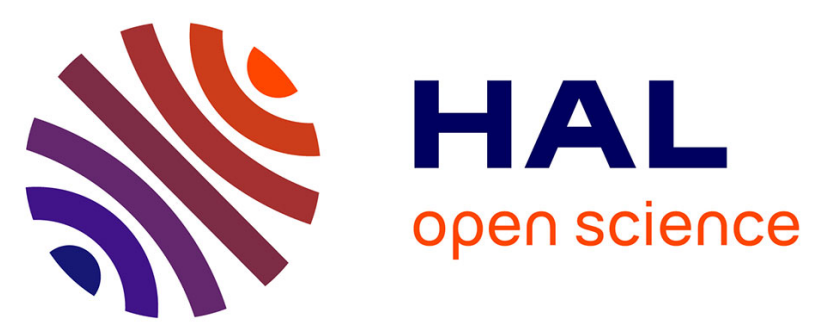

\title{
$A$ multicenter phase II study of pegylated liposomal doxorubicin in combination with irinotecan as second-line treatment of patients with refractory small-cell lung cancer
}

Nikolaos Xenidis, Nikolaos Vardakis, Ioannis Varthalitis, Stylianos Giassas, Emmanouel Kontopodis, Nikolaos Ziras, Ioannis Gioulbasanis, George Samonis, Kostas Kalbakis, Vassilis Georgoulias

\section{- To cite this version:}

Nikolaos Xenidis, Nikolaos Vardakis, Ioannis Varthalitis, Stylianos Giassas, Emmanouel Kontopodis, et al.. A multicenter phase II study of pegylated liposomal doxorubicin in combination with irinotecan as second-line treatment of patients with refractory small-cell lung cancer. Cancer Chemotherapy and Pharmacology, 2010, 68 (1), pp.63-68. 10.1007/s00280-010-1427-5 . hal-00621301

\section{HAL Id: hal-00621301 https://hal.science/hal-00621301}

Submitted on 10 Sep 2011

HAL is a multi-disciplinary open access archive for the deposit and dissemination of scientific research documents, whether they are published or not. The documents may come from teaching and research institutions in France or abroad, or from public or private research centers.
L'archive ouverte pluridisciplinaire HAL, est destinée au dépôt et à la diffusion de documents scientifiques de niveau recherche, publiés ou non, émanant des établissements d'enseignement et de recherche français ou étrangers, des laboratoires publics ou privés. 


\section{A Multicenter Phase II Study of Pegylated Liposomal Doxorubicin in Combination with Irinotecan as Second-Line Treatment of Patients with Refractory Small-Cell Lung Cancer}

Nikolaos Xenidis ${ }^{\mathrm{a}}$ Nikolaos Vardakis ${ }^{\mathrm{b}}$ Ioannis Varthalitis $^{\mathrm{c}}$ Stylianos Giassas $^{\mathrm{d}}$ Emmanouel Kontopodis ${ }^{\mathrm{b}}$ Nikolaos Ziras ${ }^{\mathrm{e}}$ Ioannis Gioulbasanis ${ }^{\mathrm{b}}$ George Samonis ${ }^{\mathrm{b}}$ Kostas Kalbakis $^{b}$ Vassilis Georgoulias ${ }^{b}$

${ }^{a}$ Department of Medical Oncology, University General Hospital of Alexandroupolis, Greece

${ }^{\mathrm{b}}$ Department of Medical Oncology, University General Hospital of Heraklion, Greece ${ }^{\mathrm{c}}$ Department of Medical Oncology, "Agios Georgios” General Hospital of Chania, Creece

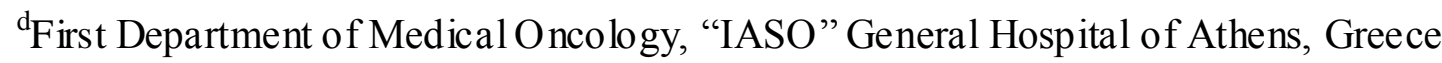
eFirst Department of Medical Oncology, "METAXA" Anticancer Hospital of Piraeus, Greece

Running title: CPT-11 plus pegylated doxorubicin salvage treatment in SCSL

Acknowledge ments: This work was partly supported by a research grant from the Cretan Association for Biomedical Research (CABR)

To whom correspondence should be addressed: Vassilis Georgoulias, $\mathrm{MD}, \mathrm{PhD}$, Department of Medical Oncology, University General Hospital of Heraklion, 71110 Heraklion, Crete, Greece

Tel: +30 2810 392783, Fax: +30 2810 392857, E- mail: georgsec@ med.uoc.gr 


\section{Abstract}

Purpose To evaluate efficacy and toxicity of a combination of pegylated liposomal doxorubicin and irinotecan in patients with refractory small-cell lung cancer.

Patients and methods Thirty-one patients with early relapse after first-line therapy with cisplatin/etoposide were treated with pegylated liposomal doxorubicin $15 \mathrm{mg} / \mathrm{m}^{2}$ and irinotecan $125 \mathrm{mg} / \mathrm{m}^{2}$ on days 1 and 15 . Treatment was repeated every 28 days.

Results A total of 144 chemotherapy courses were administered. All patients were evaluable for toxicity and twenty-six (84\%) for response. Grade 3 neutropenia occurred in two $(6.5 \%)$ patients and grade 1 thrombocytopenia in one $(3.2 \%)$. Fatigue was the most frequent grade 3 non-haematologic toxicity and was observed in seven patients (23\%). Four (12.9\%; 95\% C.I: $1.1 \%-24.7 \%)$ patients achieved a partial response and disease stabilization was observed in additional two (6.5\%) patients (Tumor Growth Control: 19.4\%; 95\% C.I: 5.5\%-33.3\%). The median TTP was 2.03 months and the median survival time was 3.16 months.

Conclusions The combination of pegylated doxorubicin and irinotecan is very well tolerated but with modest activity in patients with refractory SCLC.

Keywords Pegylated Doxorubicin; CPT-11; SCLC, Second line treatment 


\section{Introduction}

Small cell lung cancer (SCLC) is staged as limited or extensive disease according to a two-stage system developed by the Veteran's Administration Lung Cancer study group based on whether the disease can be encompassed within a reasonable radiation port. Patients with limited disease are treated with combined chemo-radiotherapy with the potential of cure, but these patients represent only about one third of the cases [1]. In the majority of patients, disease is diagnosed as extensive and treatment is undertaken with palliative intent. Chemotherapy is the backbone of therapy at any stage of disease. Platinum-based regimens remain the treatment of choice in the firstline setting. Cisplatin or carboplatin in combination with etoposide is the gold standard treatment achieving response rates ranging between $60 \%$ and $90 \%$ depending on the stage of the disease $[2 ; 3]$.

Despite the initial high chemotherapy sensitivity, SCLC remains an incurable disease, as the majority of the patients relapse commonly within the first year after initial treatment [4]. The probability of response to second line chemotherapy is mostly dependent on the treatment-free interval after the completion of first-line treatment [5]. In patients relapsing at intervals of 3 months or longer from the frontline chemotherapy, re-administration of the induction regimen is frequently associated with a new response which may substantially impact survival of SCLC patients [6]. Patients progressing while on treatment or within 3 months after its completion are considered as resistant to the drugs used in the induction regimen. For these patients various alternative combinations with drugs that have demonstrated activity in chemotherapy-naive SCLC patients have been tested in several clinical trials but with modest or borderline activity [7]. 
The effectiveness of doxorubicin-containing regimens in the treatment of SCLC has been demonstrated several years ago. Pegylated liposomal doxorub icin is a novel formulation of doxorubicin in which the drug is encapsulated in polyethylene glycol-coated liposomes. This is associated with an enhanced uptake by cancer cells and reduced drug delivery to normal tissues [8]. The substitution of doxorubicin by pegylated liposomal doxorubicin in the $\mathrm{CAV}$ regimen (cyclophosphamide, doxorubicin and vincristine) represents an active option in relapsed SCLC patients, with acceptable response and manageable toxicity [9].

Irinotecan is a semisynthetic derivative of camptothecin. The inhibition of topoisomerase-I by its active metabolite SN-38 eventually leads to double-strand DNA breakage and termination of both DNA replication and transcription [10]. The efficacy of irinotecan in the first-line treatment of SCLC has been established. The substitution of etoposide by irinotecan in platinum-based regimens provides at least the same clinical benefit with less hematologic toxicity [11]. As second-line treatment, irinotecan has been extensively evaluated in several phase II clinical trials demonstrating substantial activity, either as single agent [12], or in combinations with cisplatin [13], etoposide [14] or gemcitabine [15].

Based on these data and in preclinical studies that have shown synergistic activity between topoisomerase I and II inhibitors [16;17], we designed a two-stage phase II study to evaluate the efficacy of a pegylated doxorubicin-irinotecan combination in patients with refractory SCLC. The doses and schedule employed was based on unpublished data of a phase I study in patients with advanced solid tumors conducted by Hellenic Oncology Research Group. In this study, the maximum tolerated dose for pegylated doxorubicin and irinotecan was $15 \mathrm{mg} / \mathrm{m}^{2}$ and $125 \mathrm{mg} / \mathrm{m}^{2}$, 
respectively, given in a biweekly schedule on days 1 and 15 every 28 days. The dose limiting toxicities were grade 4 neutropenia and grade 3 thrombocytopenia.

\section{Patients and Methods}

\section{Patients}

Patients who were eligible for this study were at least 18 years old with a WHO performance status of $0-2$, an estimated life expectancy $>3$ months, histologically or cytologically proven SCLC and documented progressive disease within 3 months after the completion of first line chemotherapy with cisplatin and etoposide. Patients with brain metastases were allowed provided that they had been irradiated and had clinical and radiological improvement. Additional eligibility criteria included: adequate hematologic parameters (absolute granulocyte count $>1500 / \mathrm{mm}^{3}$, platelet count $>100,000 / \mathrm{mm}^{3}$ and hemoglobin level $>9 \mathrm{~g} / \mathrm{dL}$ ), adequate hepatic (serum bilirubin $<1.5 \mathrm{mg} / \mathrm{dL}$, transaminases $<2 \mathrm{x}$ the upper limit of normal) and renal function (serum creatinine $<1.5 \mathrm{mg} / \mathrm{dL}$ ); adequate cardiac function (left ventricular ejection fraction $>45 \%$ ). Patients with pre-existing severe diarrhea, uncontrolled angina pectoris, myocardial infarction less than 3 months before the enrolment were excluded from the study. Patients with severe cachexia or malnutrition ( $>20 \%$ loss of body weight), active infection, or a second primary tumor other than skin squamous cell carcinoma or in situ cervical carcinoma, were not eligible. The study protocol was approved by the Ethical and Scientific Committee and all patients gave a written informed consent before enrolment. 
Treatment Schedule and Dose Modifications

Pegylated doxorubicin was administered as a 1-h intravenous infusion at a dosage of $15 \mathrm{mg} / \mathrm{m}^{2}$ followed by irinotecan administered as a $90 \mathrm{~min}$ infusion at a dosage of $125 \mathrm{mg} / \mathrm{m}^{2}$ with both drugs being given on days 1 and 15 in an outpatient setting. All patients received anti-emetic therapy consisting of an intravenous 5-HT3 antagonist. The treatment cycles were repeated every 4 weeks until disease progression, unacceptable toxicity or patient's refusal to continue further treatment.

Minimum requirements for chemotherapy administration were an absolute neutrophil count $>1500 / \mathrm{mm}^{3}$, platelets count $\geq 75,000 / \mathrm{mm}^{3}$, and no grade 2 or higher non-hematologic toxicity. In case of grade $3 / 4$ or febrile neutropenia granulocytecolony stimulating factor (rhG-CSF) was administered on days 3 to 9 after chemotherapy. If febrile or grade $3 / 4$ neutropenia occurred despite rhG-CSF administration, both drug doses were adjusted to $75 \%$ of the calculated dose. A similar reduction was done in case of grade $3 / 4$ thrombocytopenia. In case of any grade 3/4 non-hematological toxicity (except nausea/vomiting and alopecia) both drug doses reduced by $15 \%$. Additional $10 \%$ dose reduction was applied in case of repeated grade 3 or 4 non-hematological toxicity.

Baseline and follow-up assessments

The baseline assessment had to be performed within 2 weeks before study entry and included a complete medical his tory and physical examination, complete blood count (CBC) with differential and platelet count, blood chemistry, computed tomography (CT) scans of the chest, abdomen and brain and whole body bone scans. Left ventricular ejection fraction (LVEF) was monitored by echocardiography or multiplegated acquisition scan at the baseline assessment and every 3 cycles of therapy; 
electrocardiography was performed as clinically indicated. During treatment, a limited history taking, physical examination, assessment of toxicity, complete blood cell count with differentials and blood chemistry were performed before each chemotherapy administration.

All patients who received at least 3 cycles were evaluable for response. Response was assessed by CT scans every 3 cycles or sooner, if clinically indicated, using the Response Evaluation Criteria in Solid Tumors (RECIST 1.0) [18]. All patients who received at least one cycle were evaluable for toxicity. Toxicity was evaluated according to the National Cancer Institute-Common Toxicity Criteria (version 2.0) [19].

\section{Statistical considerations}

Sample size was based on overall response rate. According to Simon's two-stage optimal design [20], assuming that the expected overall response rate will be at least $25 \%$ and the minimum acceptable response rate $5 \%$, a sample of 22 patients will be required in the first step. If a minimum of 2 responses is observed a total of 30 patients will be accrued. Thereby, if at least 5 responses occur the treatment will be declared sufficiently promising. The probability of accepting a treatment with a real response rate of less than or equal to $5 \%$ will be $5 \%$. On the other hand, the risk of rejecting a treatment (at the second stage) with a response rate of at least $25 \%$ will be $10 \%$.

An intent-to-treat analysis was performed. Response rate, the primary end point of the study, was calculated as the ratio of the number of patients who achieved a complete or partial response to the number of enrolled patients. All responses were confirmed 4 weeks after the first documentation of response, and imaging studies 
were reviewed by an external panel of radiologists. Secondary end points were: time to progression (TTP, determined by the interval between the initiation of treatment to the first date that disease progression was objectively documented), overall survival (OS, calculated from study entry to death or last contact), and safety. OS and PFS were assessed by the Kaplan-Meier method and the $95 \%$ confidence interval (95\% CI) for the median time to event was computed.

\section{Results}

\section{Patient characteristics}

From April 2004 to September 2009, 31 consecutive patients with refractory SCLC were enrolled onto the study. The median age was 64 years (range 48-77). Twenty-six (84\%) patients had ECOG PS of 0-1. All had received cisplatin/etoposide in the frontline setting. Median interval between prior treatment and study entry was 2.4 months (range, 0.03-3 months). Baseline patients' characteristics are shown in Table 1.

\section{Drug administration}

A total of 144 chemotherapy cycles were administered (median: 4, range: 1-20). Twenty (14\%) chemotherapy cycles were delayed for the following reasons: hematologic toxicity $(n=3)$, non-hematologic toxicity $(n=1)$ and other reasons notrelated to disease or treatment (pending imaging studies for treatment evaluation and patients' request for personal reasons; $n=16$ ). The median treatment delay was 7 days (range, 3-11 days). In 40 (28\%) chemotherapy cycles, rhG-CSF administration was required. Dose modification was required in 4 cycles due to hematologic $(n=1)$ and non-hematologic $(n=3)$ toxicity. The median delivered dose intensity for pegylated 
doxorubicin was $7.27 \mathrm{mg} / \mathrm{m}^{2} /$ week ( $97 \%$ of the protocol planned dose) and for irinotecan $60 \mathrm{mg} / \mathrm{m}^{2} /$ week ( $96 \%$ of the protocol planned dose).

\section{Toxicity}

All patients were evaluable for toxicity. The treatment was generally well tolerated. Treatment related adverse events are shown in Table 2. Two (6.5\%) patients developed grade 3 neutropenia and one (3.2\%) grade 2 thrombocytopenia. There was no febrile episode. Anemia was relatively mild, but more frequent; grade 1/2 anemia was observed in $25(80 \%)$ patients. The most significant grade 3 non-haematologic toxicity was fatigue which was observed in seven (23\%) patients. Grade 3 diarrhea occurred in one $(3.2 \%)$ patient, grade 2 in two $(6.5 \%)$ and grade 1 in three $(9.7 \%)$ patients. Hand-foot syndrome grade 1 and 2 occurred in two (6.5\%) and one (3.2\%) patients, respectively. Other non-hematologic toxicities were mild consisting mainly of grade $1 / 2$ nausea in five $(16 \%)$ patients, grade $1 / 2$ constipation in three $(9.7 \%)$ and grade $1 / 2$ alopecia (48\%). There was no toxic death.

\section{Response to Treatment and Survival}

Twenty-six (84\%) patients were evaluable for response. Five patients discontinued chemotherapy before the first evaluation; three refused further therapy after first or second cycle and two patients were dropped out after the second cycle due to performance status deterioration. Non-evaluable patients were included in the intentto-treat analysis.

Four $(12.9 \%)$ patients achieved a partial response. Two additional patients $(6.5 \%)$ experienced stabilization of their disease. The overall disease control rate was 19.4\%. After a median follow-up period of 18.8 months (range, 0.9-24 months) all 
patients had disease progression. The median TTP (Fig. 1) for patients with progression disease was 1.86 months (range: 0.5-4.97 months) and for patients with stable disease or partial response 8.63 months (range: 1.73-11.6 months). Twenty-five of 31 patients have died during the follow-up period. The median overall survival was 3.16 months (range: 0.9-24 months; 95\% CI: 1.8-4.5 months) and the 1-year survival rate $19.9 \%$ (Fig. 2).

\section{Discussion}

Today, there are more than 80 published studies of second-line therapy in SCLC reporting response rates ranging from $0 \%$ to $73 \%$ providing conflicting conclusions, especially for refractory patients [21]. The efficacy of second line chemotherapy in relapsed SCLC is largely dependent on the treatment-free interval, the extent of response and the residual toxicity from first-line therapy, as well as the performance status of the patient $[22 ; 23]$. Nevertheless, even in late relapse, treatment with other agents is often less effective than the initial chemotherapy; the response rate with the approved second-line therapy, topotecan, is only about 20\% [24]. For patients who fail to respond to or who relapsed shortly after the completion of first-line chemotherapy the response to most agents or regimens is poor and currently there is no standard second-line treatment [7].

In our study, the combination of pegylated doxorubicin and irinotecan demonstrated modest activity in refractory SCLC, with confirmed responses in $12.9 \%$ of patients; moreover, disease stabilization occurred in an additional $6.5 \%$ of the patients along with a median TTP of about 2 months and an overall survival of 3.1 months. Even if the efficacy outcomes achieved are considered comparable to those seen in other studies, the pre-defined criteria for characterizing the treatment effective 
were not met. A possible explanation for the modest efficacy of the regimen could be the relatively low dosing of the combination. As we have already discussed, the dose and schedule was based on a previous phase I study in patients with refractory neoplasms who had received multiple lines of treatment. The latter may have impacted the defined maximum tolerated dose at the combination in that phase I study. In the present study the majority of our patients had a performance status of $0-1$ and this may also account for the acceptable tolerance of the chemotherapy regimen.

Indeed, with respect to toxicity, the regimen was very well tolerated and treatment-related adverse effects were mild and easily manageable. Grade 3 neutropenia was observed only in two $(6.5 \%)$ patients but was of short duration and easily manageable with rhG-CSF. There were no episodes of febrile neutropenia. Severe anemia and thrombocytopenia were infrequent with only one patient experiencing grade 3 anemia. Regarding the non-haematologic toxicity, only fatigue was a treatment problem. Although it is difficult to differentiate this type of toxicity from the symptoms of a generalized disease such as SCLC, grade 2-3 fatigue affected fourteen $(45 \%)$ patients. Biweekly administration of irinotecan may be an additional reason for the high incidence of this type of toxicity. The rare incidence of severe hand-foot syndrome (only 10\% of patients' experienced grade 1 and 2 hand-foot syndrome) could be attributed to the relative low dose of pegylated doxorubicin administered $\left(15 \mathrm{mg} / \mathrm{m}^{2}\right.$ every 14 days).

In conclusion, although the results presented here are from a relatively small phase II study and the study was not designed to draw strong conclusions, the results suggest that pegylated doxorubicin plus irinotecan combination after early failure to cisplatin/etoposide is well tolerated, but with modest activity. However, given the mild toxicity profile of the regimen, it would merit further investigation at different 
doses or schedule in patients with refractory SCLC. Another possibility could be the replacement of pegylated doxorubicin with amrubicin, a third generation synthetic anthracycline, with potentially promising results, either as monotherapy [25], or in combination with topoisomerase-I inhibitor topotecan [26].

\section{Disclosures}

None 


\section{References}

1. Fried DB, Morris DE, Poole C, Rosenman JG, Halle JS, Detterbeck FC, Hensing TA, Socinski MA (2004) Systematic review evaluating the timing of thoracic radiation therapy in combined modality therapy for limited-stage small-cell lung cancer. J Clin Oncol 22: 4837-4845

2. Brahmer JR, Ettinger DS (1998) Carboplatin in the Treatment of Small Cell Lung Cancer. Oncologist 3: 143-154

3. Pujol JL, Carestia L, Daures JP (2000) Is there a case for cisplatin in the treatment of small-cell lung cancer? A meta-analysis of randomized trials of a cisplatin-containing regimen versus a regimen without this alkylating agent. Br J Cancer 83: 8-15

4. Jackman DM, Johnson BE (2005) Small-cell lung cancer. Lancet 366: 13851396

5. Huisman C, Postmus PE, Giaccone G, Smit EF (1999) Second-line chemotherapy and its evaluation in small cell lung cancer. Cancer Treat Rev 25: 199-206

6. Postmus PE, Berendsen HH, van ZN, Splinter TA, Burghouts JT, Bakker W (1987) Retreatment with the induction regimen in small cell lung cancer relapsing after an initial response to short term chemotherapy. Eur J Cancer Clin Oncol 23: 1409-1411

7. Hurwitz JL, McCoy F, Scullin P, Fennell DA (2009) New advances in the second-line treatment of small cell lung cancer. Oncologist 14: 986-994

8. Hong RL, Huang CJ, Tseng YL, Pang VF, Chen ST, Liu JJ, Chang FH (1999) Direct comparison of liposomal doxorubicin with or without polyethylene 
glycol coating in C-26 tumor-bearing mice: is surface coating with polyethylene glycol beneficial? Clin Cancer Res 5:3645-3652

9. Leighl NB, Goss GD, Lopez PG, Burkes RL, Dancey JE, Rahim YH, Rudinskas LC, Pouliot JF, Rodgers A, Pond GR, Shepherd FA (2006) Phase II study of pegylated liposomal doxorubicin $\mathrm{HCl}$ (Caelyx) in combination with cyclophosphamide and vincristine as second-line treatment of patients with small cell lung cancer. Lung Cancer 52: 327-332

10. Carboni MC, Coderoni S (1994) Effect of CPT on the DNA cleavage/religation reaction mediated by calf thymus Topoisomerase I: evidence of an inhibition of DNA religation. Inhibition of Topoisomerase Imediated DNA religation by CPT. Mol Biol Rep 20: 129-133

11. Natale R, Lara P, Chansky K (2008) S0124: A randomized phase III trial comparing irinotecan/cisplatin (IP) with etoposide/cisplatin (EP) in patients (pts) with previously untreated extensive stage small cell lung cancer (ESCLC). J Clin Oncol26[20 suppl] Ref Type: Abstract

12. Masuda N, Fukuoka M, Kusunoki Y, Matsui K, Takifuji N, Kudoh S, Negoro S, Nishioka M, Nakagawa K, Takada M (1992) CPT-11: a new derivative of camptothecin for the treatment of refractory or relapsed small-cell lung cancer. J Clin Oncol 10: 1225-1229

13. Sandler A (2002) Irinotecan plus cisplatin in small-cell lung cancer. Oncology (Williston Park) 16: 39-43

14. Masuda N, Matsui K, Negoro S, Takifuji N, Takeda K, Yana T, Kobayashi M, Hirashima T, Kusunoki Y, Ushijima S, Kawase I, Tada T, Sawaguchi H, Fukuoka M (1998) Combination of irinotecan and etoposide for treatment of refractory or relapsed small-cell lung cancer. J Clin Oncol 16: 3329-3334 
15. Rocha-Lima CM, Herndon JE, Lee ME, Atkins JN, Mauer A, Vokes E, Green MR (2007) Phase II trial of irinotecan/gemcitabine as second-line therapy for relapsed and refractory small-cell lung cancer: Cancer and Leukemia Group B Study 39902. Ann Oncol 18: 331-337

16. Cortes F, Pinero J (1994) Synergistic effect of inhibitors of topoisomerase I and II on chromosome damage and cell killing in cultured Chinese hamster ovary cells. Cancer Chemother Pharmacol 34:411-415

17. Eder JP, Chan V, Wong J, Wong YW, Ara G, Northey D, Rizvi N, Teicher BA (1998) Sequence effect of irinotecan (CPT-11) and topoisomerase II inhibitors in vivo. Cancer Chemother Pharmacol 42: 327-335

18. Therasse P, Arbuck SG, Eisenhauer EA, Wanders J, Kaplan RS, Rubinstein L, Verweij J, Van GM, van Oosterom AT, Christian MC, Gwyther SG (2000) New guidelines to evaluate the response to treatment in solid tumors. European Organization for Research and Treatment of Cancer, National Cancer Institute of the United States, National Cancer Institute of Canada. J Natl Cancer Inst 92:205-216

19. Trotti A, Byhardt R, Stetz J, Gwede C, Corn B, Fu K, Gunderson L, McCormick B, Morrisintegral M, Rich T, Shipley W, Curran W (2000) Common toxicity criteria: version 2.0. an improved reference for grading the acute effects of cancer treatment: impact on radiotherapy. Int J Radiat Oncol Biol Phys 47: 13-47

20. Simon R (1989) Optimal two-stage designs for phase II clinical trials. Control Clin Trials 10:1-10

21. Tiseo M, Ardizzoni A (2007) Current status of second-line treatment and novel therapies for small cell lung cancer. J Thorac Oncol 2:764-772 
22. Kim YH, Goto K, Yoh K, Niho S, Ohmatsu H, Kubota K, Saijo N, Nishiwaki Y (2008) Performance status and sensitivity to first-line chemotherapy are significant prognostic factors in patients with recurrent small cell lung cancer receiving second- line chemotherapy. Cancer 113: 2518-2523

23. Sundstrom S, Bremnes RM, Kaasa S, Aasebo U, Aamdal S (2005) Secondline chemotherapy in recurrent small cell lung cancer. Results from a crossover schedule after primary treatment with cisplatin and etoposide (EPregimen) or cyclophosphamide, epirubicin, and vincristin (CEV-regimen). Lung Cancer 48: 251-261

24. Cheng S, Evans WK, Stys-Norman D, Shepherd FA (2007) Chemotherapy for relapsed small cell lung cancer: a systematic review and practice guideline. $\mathbf{J}$ Thorac Oncol 2: 348-354

25. Inoue A, Sugawara S, Yamazaki K, Maemondo M, Suzuki T, Gomi K, Takanashi S, Inoue C, Inage M, Yokouchi H, Watanabe H, Tsukamoto T, Saijo Y, Ishimoto O, Hommura F, Nukiwa T (2008) Randomized phase II trial comparing amrubicin with topotecan in patients with previously treated smallcell lung cancer: North Japan Lung Cancer Study Group Trial 0402. J Clin Oncol 26: 5401-5406

26. Nogami N, Kiura K, Takigava N, Harita S, Chikamori K, Shibayama T, Tabata M, Hotta K, Shinkai T, Tanimoto M (2010) A phase II trial of combination chemotherapy with topotecan and amrubicin in small cell lung cancer (SCLC). J Clin Oncol 28:15s Ref Type: Abstract 
Table 1 Patient characteristics

\begin{tabular}{lcc}
\hline Characteristic & $\boldsymbol{n}$ & $\boldsymbol{\%}$ \\
\hline Number of patients & 31 & \\
Evaluable for response & 26 & \\
Evaluable for toxicity & 31 & \\
Age, years (range) & $64(48-77)$ & \\
Gender & & \\
$\quad$ Male & 28 & 90.3 \\
Female & 3 & 9.7 \\
Performance status & & \\
0 & 5 & 16.1 \\
1 & 21 & 67.7 \\
2 & 5 & 16.1 \\
No. of distant metastatic sites & & \\
1 & 1 & 3.2 \\
2 & 8 & 25.8 \\
$\geq 3$ & 22 & 71.0 \\
Metastatic sites & & \\
Liver & 16 & 51.6 \\
Nodes & 21 & 67.7 \\
Lung & 27 & 87.1 \\
Bones & 8 & 25.8 \\
CNS & 7 & 22.6 \\
Pleura & 7 & 22.6 \\
Other & 10 & 32.3 \\
\hline
\end{tabular}


Table 2 Hematologic and non-hematologic toxicity

\begin{tabular}{lcccc}
\hline Toxicity & \multicolumn{5}{c}{ WHO grade } \\
\hline & $\mathbf{1}$ & $\mathbf{2}$ & $\mathbf{3}$ & $\mathbf{4}$ \\
Neutropenia & $\mathrm{n}(\%)$ & $\mathrm{n}(\%)$ & $\mathrm{n}(\%)$ & $\mathrm{n}(\%)$ \\
\cline { 2 - 5 } Febrile Neutropenia & $7(22.6)$ & $3(9.7)$ & $2(6.5)$ & - \\
Anemia & -- & -- & - & - \\
Thrombocytopenia & $19(61.3)$ & $6(19.4)$ & $1(3.2)$ & - \\
Nausea & $6(19.4)$ & $1(3.2)$ & - & - \\
Vomiting & $2(6.5)$ & $3(9.7)$ & - & - \\
Constipation & -- & $2(6.5)$ & - & - \\
Diarrhea & $2(6.5)$ & $1(3.2)$ & - & - \\
Stomatitis & $3(9.7)$ & $2(6.5)$ & $1(3.2)$ & - \\
Hand-Foot Syndrome & $3(9.7)$ & -- & - & - \\
Neurotoxicity & $2(6.5)$ & $1(3.2)$ & - & - \\
Allergy & $3(9.7)$ & $1(3.2)$ & - & - \\
Fatigue & $1(3.2)$ & $1(3.2)$ & - & - \\
Alopecia & $8(25.8)$ & $7(22.6)$ & $7(22.6)$ & - \\
\hline
\end{tabular}




\section{Legends to figures}

Fig. 1 Kaplan-Meier time to progression curve for patients with progression disease (PD) and patients with stable disease or partial response (SD/PR)

Fig. 2 Kaplan-Meier survival curve for all patients 
Figure 1

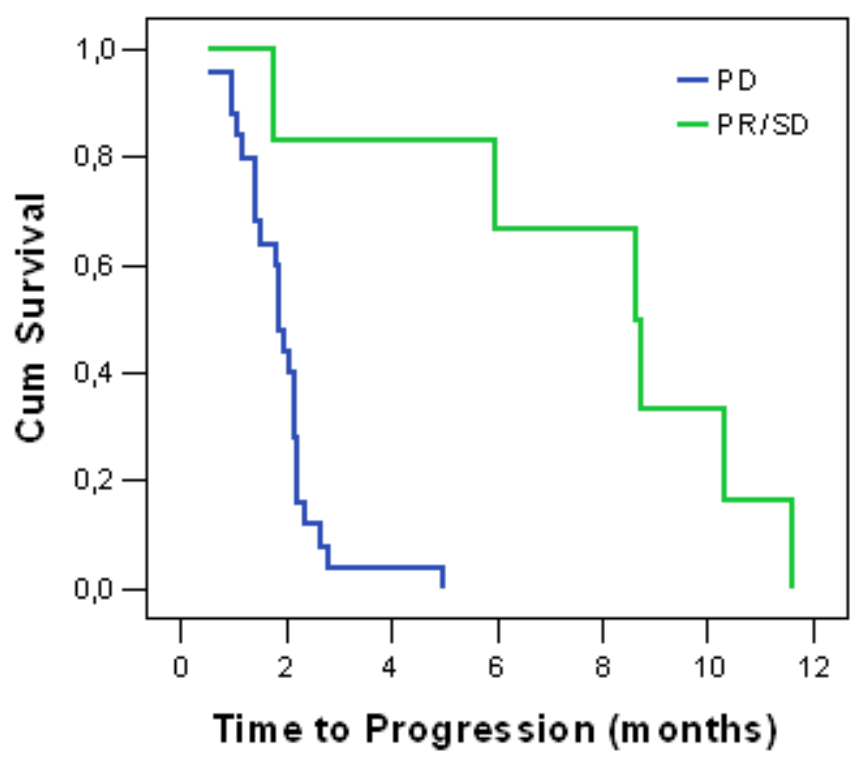


Figure 2

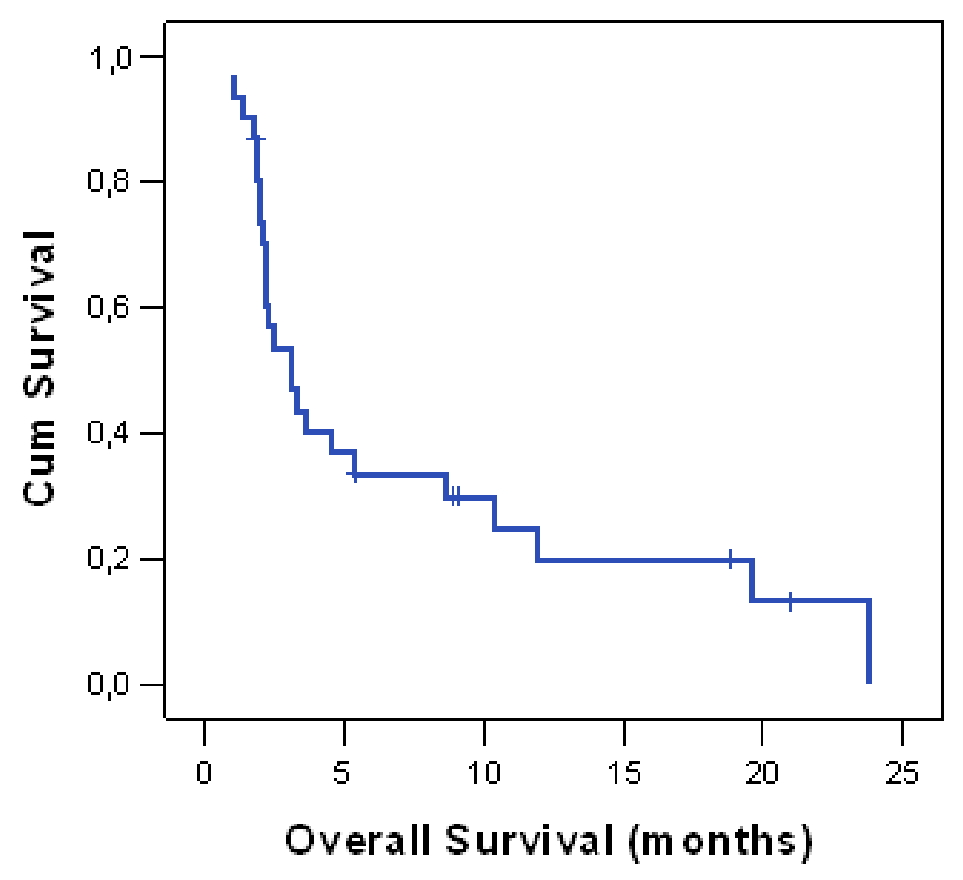

